\title{
The History of Women's Sports Medicine
}

\author{
Jo A. Hannafin, MD, $\mathrm{PhD}^{1,2}$, Lisa R. Callahan, $\mathrm{MD}^{1,3}$ \\ ${ }^{1}$ Founders, Women's Sports Medicine Center, Hospital for Special Surgery, New York, New York USA \\ 2 Sports Medicine and Shoulder Service, Hospital for Special Surgery \\ ${ }^{3}$ Primary Sports Medicine Service, Hospital for Special Surgery
}

The editorial reviews the rationale for development of Women's Sports Medicine Programs in the United States. Current issues surrounding the lack of sex-specific analysis in the published literature are reviewed. There is an ongoing need for basic, translational, and clinical research in optimizing care of female athletes and active women of all ages. The importance of the newly established Journal of Women's Sports Medicine in fulfilling that need is discussed.

We met, by chance, on a cold New York spring day in 1994. We had both taken our first small steps as pioneers in our fields. Jo had completed the prestigious HSS sports medicine fellowship, the first female orthopedic surgeon to do so. Lisa was a junior faculty member at Stanford, where she had been the inaugural primary care sports medicine fellow. We connected over our experiences as rare sports medicine physicians who were female; we bonded over the knee injuries we had suffered as female athletes. Discussing our practices, the types of patients who were self-referring to us, and issues with access to care for active and athletic women produced a spontaneous joint epiphany: wouldn't it be amazing to work together to build a sports medicine center for women? We envisioned a program that could provide expert clinical care, as well as integrate support services such as nutrition, psychology, and sports performance and rehabilitation, all tailored to girls and women. We also recognized a tremendous opportunity for research, as well as mentoring other women who would follow in our paths.

And thus, with the active support of HSS Surgeon-in-Chief Dr. Russell Warren, the Women's Sports Medicine Program at HSS was born. This program was the first of its kind. We have grown from humble beginnings as a program with two faculty members into a Women's Sports Medicine
Center with a fourteen-member multidisciplinary group of women whose collective resumes are deep and impressive. Our ranks include physicians in primary care and physiatry, orthopedic sports medicine surgeons, and specialists in nutrition, sports psychology, physical therapy and sports performance. Our faculty provide care to competitive youth, college, elite and professional athletes as well as recreational athletes of all ages. Members of the HSS Women's Sports Medicine Center have served as team physicians for multiple national teams including US Rowing, USA Basketball, USA Lacrosse, USA Biathalon, Ski and Snowboard, USA Women's Gymnastics, and USA Track and Field. Our physicians have provided coverage for multiple summer and winter Olympic Games, World Championships/World Cups, and served as team physicians for professional women's soccer and basketball teams.

Members of the WSMC have a robust interest in education, beginning with our patients and extending to physical therapists, medical students, residents and fellows. This focus on education resulted in the development of the extremely popular WSMC summer internship program, which provides an immersive experience for college and medical students 
interested in any aspect of women's sports medicine. Many have gone on to promising careers in orthopaedic surgery, primary care sports medicine and physical therapy, continuing the growth of our young but critical field.

We are humbled and gratified to see Women's Sports Medicine Programs and Centers develop across the country, and to see physicians and surgeons who have trained at HSS pursue the development of women's sports medicine centers as a part of their careers. Training the next generation of physicians, physical therapists, performance specialists, sports psychologists and nutritionists who have a specific interest in the care of the female athlete continues to be a hallmark of the HSS WSMC.

In 2020, Mary Mulcahey and co-authors published a paper on Women's Sports Medicine Programs in the US1. The study was designed to determine the number of WSMPs and explore program characteristics such as geographic location, specialties represented, common conditions treated, program history, and patient population. Nineteen WSMPs were identified, with the majority being in existence for 6 to 10 years $(44.4 \%)$. The majority of programs had two physicians and the most common conditions treated were patellofemoral pain syndrome (33.3\%), stress fracture $(33.3 \%)$, and ACL tear $(22.2 \%)$. The programs were noted to address conditions known to have a higher incidence in the active female population, however the WSMPs were not solely geared towards the treatment of female athletes.

But there is much more work to be done. The healthcare world is just beginning to recognize the importance of sex, and gender, in clinical and research issues of the female athletic patient. There are tremendous opportunities to expand our knowledge on the role of sports in optimization of health, the epidemiology of sports injury, injury prevention, the physiology of the female athlete and differences in performance and sports related injury across the lifetime of the athlete. It is well accepted that many conditions, ranging from ACL tears to concussion to RED-S and bone stress injuries, are consistently reported to be more frequent in females. But as delineated by our HSS WSMC colleague Dr. Ellen Casey et $\mathrm{al}^{2}$, there is little understanding of the sex-specific factors that can improve clinical management, such as prescribing appropriate prehabilitation to guiding post-injury rehabilitation and return to play.
Similarly, currently lacking in orthopaedic surgery is the study of sex as an independent variable in response to surgical and non-surgical treatment, recovery and return to sports. Twenty years ago, the Institute of Medicine released a report stating that sex must be considered in all aspects and at all levels of biomedical research. Knowledge of differences between males and females in responses to treatment serves to improve our ability to care for our patients. A study published in $2015^{3}$ assessed the presence of sex-specific reporting in 3 time periods (2000,2005 and 2010) and included subspecialty and general orthopaedic journals. Overall, the proportion of sex-specific analyses increased during the three times periods studied but was present in less than $1 / 3$ of the studies. A similar study performed in $2020^{4}$ reported on sexspecific analysis (SSA) in three high impact orthopaedic sports medicine journals in 2011 and 2016. $44.4 \%$ of the overall study population was female, however only $30.5 \%$ of the studies included patient sex as variable in a multifactorial statistical model. The proportion of studies that performed SSA did not differ between 2011 and 2016 and of note did not differ significantly from the data published in 2015. Of the 293 studies that reported SSA, 91 (31\%) demonstrated a significant difference in outcomes following anterior cruciate ligament, medial patellofemoral ligament, and posterior cruciate ligament reconstruction; autograft preparation; postoperative use of opiates following arthroscopy; and recovery after sports-related concussions.

There have been slow but significant changes in access to sports opportunities for high school and collegiate women since the passage of Title IX in 1972, as well as the continued expansion of opportunities for professional and elite athletes. This change in sports exposure and high school, club and collegiate athletics has resulted in increased participation in sports and fitness by women throughout their lifetime. It is critical to remember that research in the field of women's sports medicine is not limited to the high school, collegiate or elite athlete. Research in sex differences in sports medicine epidemiology, treatment of sports injuries and outcomes is open to significant improvement. Sex-specific subgroup analysis and reporting must be included in clinical publications as those data can generate hypotheses regarding sex differences for subsequent research and can also be utilized in systematic reviews where large 
independent studies may not be available in the literature. Prospective studies evaluating conditions that affect males and females should be designed with sufficient sample size to allow for subgroup analysis by sex to be performed and should include sex-specific differences among the research questions.

Thus, the time is right for the creation of a journal dedicated to the health of the active female patient. In addition to becoming a strong and vibrant vehicle for addressing important scientific questions, this journal has the opportunity to be a unique and powerful tool for connecting, mentoring, and supporting the talented professionals who become the future leaders in this arena. We are honored to lend our voices and our passion to the promising future of this young but important field.

\section{Conflict of Interest Statement}

The authors report no conflict of interest with the contents of this manuscript.

\section{Corresponding Author}

Jo A. Hannafin, MD, PhD

Hospital for Special Surgery

535 East 70th Street
New York, NY 10021

203-609-1514

hannafinj@hss.edu

\section{REFERENCES}

1. Hayes, MK, Brown S, Mulcahey MK. Women's Sports Medicine Programs in the United States: an interdisciplinary approach to the care of girls and women. Phys Sportsmed. 2020 Feb;48(1):8185. doi: 10.1080/00913847.2019.1632157. Epub 2019 Jun 28. PMID: 31213108 [Indexed for MEDLINE]

2. Lin CY, Casey E, Herman DC, Katz N, Tenforde AS. Sex differences in common sports injuries. PM R. 2018 Oct; 10(10):1073-1082. doi 10.1016/j.pmrj.2018.03.008. Epub 2018 Mar14.

3. Hettrich, CM, Hammoud, S, LaMont, LE, Arendt, EA, Hannafin, JA. Sex-specific analysis of data in high-impact orthopaedic journals: How are we doing? Clin Orthop Rel Res. Sept 24(9):2818-4, doi 10.1177/0363546515578838 Dec; 473(12):3700-3704. Epub 2015 Jul 22

4. Gianakos, AL, Szukics, P, George, N, Elkattawy, S, LaPorte, M, Mulcahey, MK. Sex-specific analysis at two time points in three high-impact orthopaedic sports medicine journals. Arthrosc Sports Med Rehabil. 2020 Apr 28;2(3):e207-e212. doi: 10.1016/j.asm.2020.02.002. eCollection 2020 Jun. 